Bond University

Research Repository

\title{
Variations in the offence actions of deliberate firesetters
}

\section{A cross-national analysis}

Fritzon, Katarina; Doley, Rebekah; Hollows, Kerrilee

Published in:

International Journal of Offender Therapy and Comparative Criminology

DOI:

$10.1177 / 0306624 \times 13487524$

Licence:

Unspecified

Link to output in Bond University research repository.

Recommended citation(APA):

Fritzon, K., Doley, R., \& Hollows, K. (2014). Variations in the offence actions of deliberate firesetters: A crossnational analysis. International Journal of Offender Therapy and Comparative Criminology, 58(10), 1150-1165. https://doi.org/10.1177/0306624X13487524

\section{General rights}

Copyright and moral rights for the publications made accessible in the public portal are retained by the authors and/or other copyright owners and it is a condition of accessing publications that users recognise and abide by the legal requirements associated with these rights.

For more information, or if you believe that this document breaches copyright, please contact the Bond University research repository coordinator 
Running Head: CROSS-NATIONAL ANALYSIS OF FIRESETTERS

Variations in the Offence Actions of Deliberate Firesetters: A Cross-National Analysis 
CROSS-NATIONAL ANALYSIS OF FIRESETTERS

Abstract

Since Canter and Fritzon (1998) first introduced their '4D' classification system for arson, many studies have replicated the model with samples of arsonists from around the world. However scholars have reported differences in the offence actions of arsonists across samples. No study as yet, has attempted to statically examine the relevance of these differences. Using multidimensional scaling procedures and two-way chi square contingency analyses, this study examined whether cross-national differences in arson variables existed between Australian and British arsonists. The results indicated that differences did exist and further, that differences reflected the environmental characteristics of the country from which each sample was drawn. These findings have important theoretical and clinical implications, particularly for the utility of the '4D' model as an investigatory tool and for the wider arson profiling literature.

\section{Keywords}

Arson, serial arson, firesetting, offender profiling, action system theory, environmental criminology 
CROSS-NATIONAL ANALYSIS OF FIRESETTERS

The use of statistical data to make predictions about offending behaviour and offending styles has been a growing trend in the empirical literature (Fritzon, Canter \& Wilton, 2001; Hakkanen, Puolakka \& Santtila, 2004; Trojan \& Salfati, 2011). Profiling systems founded in statistical data have also been increasingly relied upon by law enforcement agencies due to their ability to produce more reliable and valid profiles. Since the introduction of Canter and Fritzon's (1998) Faceted Action Systems classification system for arson ${ }^{\mathrm{i}}$, many studies have employed the model to explain and predict the behaviour of arsonists (Canter, Bennell, Alison \& Reddy, 2003; Fritzon et al., 2001). Scholars have replicated the model with arsonists from around the world, statistically validating Canter and Fritzon's (1998) thematic findings and providing much needed empirical support for the application of the action system framework with criminal behaviour (Hakkanen et al., 2004; Kocsis \& Cooksey, 2002; Wachi et al., 2007).

Results from these studies have also indicated a propensity for differences to exist in the individual offence actions and background characteristics of arsonists across samples. The purpose of the current study was to statistically test whether cross-national differences exist, and to explore the extent to which environmental or place-based factors influence the actualisation of arson offences across international samples of arson offenders. Evaluating the impact of environmental contingencies on the expression of arson has the potential to not only assist in exploring the implications of such differences for the utility of the Faceted Action Systems classification system as an investigatory tool with international arson cases, but could also aid in developing our understanding about arson risks and responses.

Canter and Fritzon's (1998) study was especially important in that it was the first empirical study to employ quantitative scientific methods to address the limitations of the arson literature at the time, by relying on the offence actions of arsonists rather than inferred motives to classify arsonists. Grounded in Shye's (1985) Action System Theory, the Faceted 
CROSS-NATIONAL ANALYSIS OF FIRESETTERS

Action Systems model (Canter \& Fritzon, 1998) posits that criminal behaviour is a process of destructive interactions with the world. Criminal behaviours are thought to encompass two major facets; the source of action and locus of impact, with each being either external or internal to the action system. Rooted in cybernetics, action system theory aims to model sociopsychological processes as systems of interrelationships, such that an action system is one that is regarded as being open, active, stable and organised (Shye 1985). The underlying assumption of the action system framework (Shye 1985) is that the combination of the two sources of action and the two locus of impact give rise to four distinct behavioural modes of functioning or arson themes; adaptive, conservative, expressive and integrative (Canter, 2010; Canter \& Fritzon, 1998).

According to the model, arsonists can be categorised based on whether the motivating source of their crime is expressive (internal) or instrumental (external) in nature (Canter \& Fritzon, 1998). Expressive and instrumental arsonists can then also be differentiated based on the nature of the target and whether it is external (object) or internal (person) to the arsonist. Further, Canter and Fritzon (1998) identified that arsonists could be categorised based not only on their offence actions (or responses to the action system) but by their background characteristics too.

As noted previously, several studies have since tested the model by examining the offence actions and background characteristics of arsonists within the established theoretical framework and have found support for Canter and Fritzon's (1998) findings (Hakkanen et al., 2004; Kocsis \& Cooksey, 2002; Wachi et al., 2007). However, several differences in the individual offence actions of offenders were noted when the results of those studies were directly compared to the results of Canter and Fritzon's (1998) British sample.

For example, Hakkenen and colleagues (2004) found that in contrast to the British sample their Finnish sample of 433 arson cases (also derived from police data) was 
CROSS-NATIONAL ANALYSIS OF FIRESETTERS

comprised of lower frequencies of serial arsonists. They also identified that differences existed in the positioning of the offence action variables for young arson offenders. Young offenders in the Finnish sample were associated with the Expressive theme, whereas in Canter and Fritzon's (1998) study, young offenders were associated with the Adaptive theme. This suggested that in Finland, young offenders not only expressed acts of arson differently to young offenders in Britain, but were also motivated in different ways (Hakkanen, et al., 2004; Santilla, Hakkanen, Alison \& White, 2003).

Hakkanen and colleagues (2004) partially addressed this question by arguing that differences were likely to be the result of national differences and a more developed approach to crime in young British offenders. Their explanation was based on the notion that criminal behaviours evolve over time and that in juvenile arson offenders, there is a trend for arson behaviours to move away from being emotionally motivated and characterised by impulsivity and curiosity, toward being instrumentally motivated and characterised by criminal advancement (Hakkanen et al., 2004; Hickle \& Roe-Sepowitz ,2010).

Similarly, Wachi and colleagues (2007) found that differences existed in the positioning of variables relative to their dominant behavioural mode of functioning when they directly compared their results to that of the Canter and Fritzon (1998) study. For example, in their sample of Japanese female serial arsonists (obtained from police files for 83 female $\operatorname{arsonists}^{\mathrm{ii}}$ ) the variable that represented the targeting of a business was positioned within the Instrumental theme however, in the British sample that same variable was positioned within the Expressive theme.

The results of these studies indicate that while the four behavioural modes of functioning within the action system framework appear to remain consistent across national samples, differences tend to exist in the frequencies and positioning of certain arson variables, suggesting that arson offences are perhaps expressed differently according to their national 
CROSS-NATIONAL ANALYSIS OF FIRESETTERS

location. According to the environmental criminology perspective, criminal behaviour is intimately related to the environment in which it occurs and is based on the principle that all criminal behaviour is the result of a person-situation interaction (Brantingham \& Brantingham, 2004, Wortley \& Mazerolle, 2008). In this respect, environments are thought to play a fundamental role in the initiation and actualisation of crimes. Several theories exist within this field that attempt to explain criminal behaviour through means of the personsituation interaction (Cohen \& Felson, 1979; Cornish \& Clarke, 1986).

One example is Routine Activities Theory (Cohen \& Felson, 1979), which argues that crime occurs when there is an accessible target, a motivated offender and where capable guardians are absent. Also referred to as the Crime Triangle, the theory posits that offenders, through their routine daily activities, will search for and identify potential targets in their environment (Cohen \& Felson, 1979).

Further, it is important to note that arson is characterised differently across different countries, which may support the possibility that environmental or place-based factors influence the way that offenders act out their individual crimes. According to the Australian Institute of Criminology (AIC; http://www.aic.gov.au), arson is categorised as being a property offence with bushfires listed as being the most prevalent form of arson in Australia. Approximately 52,000 bushfires are estimated to occur in Australia each year. The AIC has estimated that potentially half of those bushfires are the result of deliberate or suspicious firesetting. On the United Kingdom's Home Office of Crime Statistics (HOCS; http://homeoffice.gov.uk) website, arson is also listed as a property offence. However unlike the AIC's characterisation of arson offences, the HOCS website describes arson as being a form of vandalism, which includes the deliberate destruction of property.

Drawing from this, it appears that while the range of underlying motives of arsonists are common, the actualisation of arson at the micro-level of analysis may be largely 
CROSS-NATIONAL ANALYSIS OF FIRESETTERS

influenced by contextual factors at the time of (or in the time leading up to) the act of arson (Brantingham \& Brantingham, 1981; Liem et al., 2011). For instance, Cozens and Christensen (2011) state that in Australia there is a trend for deliberately lit bushfires to occur proximal to recent developments at the urban-rural fringes of cities. Further, the authors report that almost 30 percent of deliberately lit bushfires in one Australian state were the result of abandoned and torched cars which they argued was due, in part, to offenders viewing the location as being low risk or safe (Cozens \& Christensen, 2011). In other words, the differences found in the offence actions of arsonists across samples may be a function of the offender's response to, or manipulation of, their immediate environment. These examples illustrate how environmental criminology theories and place-based factors may contribute to understandings about the differences found in the offence actions of arsonists in cases where Canter and Fritzon's (1998) Faceted Action Systems model for arson has been employed.

Significant cross-national differences in arson variables would have implications not only for the scholars who research in the area of offender profiling, but also for the law enforcement agencies which rely on profiling measures to aid investigations of arson, and for the treatment and corrective agencies addressing issues of risk, rehabilitation and prevention. Further, the integration of offender-based approaches to arson with environmental criminology approaches can contribute to the development of an arson model that is comprehensive enough to account for crimes of arson at various levels of analysis.

The purpose of the current study was to investigate whether cross-national differences exist in arson crimes, by comparing police file data for arson crimes from Australia and Britain. Consistent with Shye's (1985) action system theory, it was expected that the actions of arsonists from Australia and Britain would each be represented by the Faceted Action Systems model (Canter \& Fritzon, 1998). Specifically, it was hypothesised that the model 
CROSS-NATIONAL ANALYSIS OF FIRESETTERS

would maintain its overall theoretical structure with the actions of arsonists from each nation reflecting one of four behavioural modes of functioning.

However, based on the results of the previously discussed studies and on the notion that crimes are fundamentally influenced by the way in which the offender interacts with his/her environment, it was expected that differences would exist in the individual offence actions of arsonists across the two samples. The current study hypothesised that differences would emerge in the frequencies and positioning of some variables within the Faceted Action Systems model, when the models from each nation were compared. It was expected that differences in the offence actions of arsonists would reflect the environmental or place-based factors characteristic of the nation from which each sample was drawn

For example, based on previous Australian statistical data and that the Australian landscape is characterised by large regions of open land, it was hypothesised that the fires committed by Australian arsonists would be characterised by significantly higher frequencies of variables that reflected the selection of open bushland, such as the presence of multiple ignition points. It was also hypothesised that the variables that represented acts of setting fire to bushland would be positioned differently within the Faceted Action Systems model in Australia compared to Britain, meaning that acts of bushland firesetting would share different motivations across the two nations because the outcomes of such an act would differ greatly across the two opposed landscapes. However, it was hypothesised that for variables not representative of each region such as, having known the victim prior to setting a fire, there would be no differences in the positioning of variables within the Faceted Action Systems model across Australia and Britain.

\section{Method}

\section{Participants}


CROSS-NATIONAL ANALYSIS OF FIRESETTERS

To test the hypotheses that differences would exist in the offence actions of Australian and British firesetters, data was obtained from police files. Data for the British sample was drawn from 239 case files for crimes of arson committed between 1991 and 1996. The data consisted of the final sample contained in Fritzon (1998) and overlaps with 230 cases previously analysed and published (Fritzon, Canter, \& Wilton, 2001). Case files were provided by seven police services from across England and represented areas with varied crime rates. The majority of the participants in the British sample were male (86\%) with an age range of between 6 and 68 years $(M=24 ; \mathrm{SD}=10.68)$.

The Australian sample included data derived from 187 offenders from two Australian states for arson offences committed between 1979 and 2002. Information about the offence actions and individual characteristics of arsonists were derived from solved arson case files, provided by the relevant police service. The majority of offenders in the sample were male (91\%) with an age range of between 13 and 65 years $(M=28.39, S D=10.42)$. These data have also been previously analysed and published in Doley (2009).

\section{Statistical Analysis of Variables}

At step one of the analysis, data was subject to content analysis. The information included in police files was analysed and ordered into the Offence Action variables. The offence action variables reflected the criminal actions of perpetrators. A dichotomous approach to coding was employed with variables coded according to the presence or absence of their corresponding behaviours. In the case where an individual committed multiple acts of firesetting, the variables associated with each act of firesetting were collapsed to create a new set of variables that were representative of that individual's repertoire of firesetting behaviour.

At the second step of the analysis, cross-national data was evaluated to determine the compatibility of individual variables across the two data sets. Offence action variables were 
CROSS-NATIONAL ANALYSIS OF FIRESETTERS

assessed according to the consistency of their operational definitions, with only those variables considered to be measuring the same offence action included in the final analysis.

To achieve this, three sets of the offence action variables from the Australian sample and three sets of the offence action variables from the British sample were collapsed to create six new offence action variables that could be directly compared. For example, in one of the Australian samples the variable Planned was defined as; the offender bringing with them material for the purpose of igniting fire and included a self-reported prior intent to light a fire. This indicated that some level of planning was conducted prior to the act of arson taking place. In the British sample however, these behaviours were coded using two separate variables (materials brought, planned). In this case, the two variables in the British sample were collapsed to create a new Planned variable that would be comparable for the current study.

The benefits of using police data for offender profiling are well noted (Canter, 2004). Police records provide a certain level of objectivity that is unavailable through alternate means of data collection such as interviews and questionnaires, by eliminating the potential for researcher bias. Police data also aids in diminishing the risk of distorting data by evaluating the behaviour in its naturally occurring process. Further, Canter (2004) states that the use of data derived from police investigations in empirical research helps to bring together the two areas of criminal investigation.

The final set of variables included 23 offence action variables. A complete list of the variables and their descriptions are outlined in Appendix A. At the third step of the analysis, statistical tests were conducted to explore whether cross-national differences in arson variables existed between the Australian and British samples. These included the application of a multidimensional scaling procedure in the form of a smallest space analysis to test whether the actions of arsonists could be accounted for by the Faceted Action Systems model. 
CROSS-NATIONAL ANALYSIS OF FIRESETTERS

\section{Results}

To test the hypothesis that the correlations among actions of arsonists from Australia and Britain would be represented by the Faceted Action Systems model and one of the four behavioural modes of functioning; and to determine whether differences existed in the positioning of arson variables across the two samples, two smallest space analysis were conducted. These results are presented in Figures 1 and 2 below.

[Please insert figure 1 and figure 2 here]

Figure 1 presented the smallest space analysis results for the British data. Comparing these results to the model presented in Canter \& Fritzon (1998) and Fritzon, Canter, \& Wilton (2001), almost all variables are in their expected configurations and remain consistent to the original interpretations of the adaptive, integrative, expressive and conservative modes respectively. Furthermore, the four regions maintain the structural representation predicted by Shye's action systems hypothesis, namely that integrative actions are opposite to adaptive; and conservative actions are opposite to expressive. Only one variable is displaced from its original regional position as represented in Fritzon, Canter, \& Wilton (2001), namely witness which was located in a borderline position between Conservative and Integrative, and is now located in Integrative. It is not surprising to observe similarities between this plot and that of Fritzon, Canter \& Wilton (2001), since the cases are the same, while almost half of the variables have been removed or re-defined in order to achieve consistency with the Australian data.

Figure 2 presents the results for the Australian data. While this SSA also conforms to Shye's (1985) structural hypotheses, there are a number of differences in the positioning of variables within each of the four faceted themes. Within the Conservative region, the variables own home, and lives endangered were originally located within Integrative in Fritzon, Canter, \& Wilton (2001). These may reflect differences in the Australian cases, in 
CROSS-NATIONAL ANALYSIS OF FIRESETTERS

that Conservative arsonists may target their partner while still living with them, as opposed to the UK arsonists, who target the ex-partner when no longer living in the same home.

Additional differences are found in the Expressive region, where Australian serial arsonists appear to target schools and businesses, whereas these targets were more commonly associated with Adaptive arsonists in the UK sample.

Finally, within the Integrative region, there are a number of differences. The variables substance use and remain/return were located within the Expressive region in the UK sample, although the latter was very close to the border with Integrative and probably reflects the combination of remaining at the scene (associated with Integrative) and returning to the scene (associated with Expressive). Similarly the variables substance use includes both prescription and non-prescription medication; the former being associated with Integrative, and the latter with Expressive.

While these differences in the geometric locations of variables are still consistent with the faceted action systems model, they do appear to indicate that there are different specific behavioural variations between UK and Australian arsonists. To further test the hypotheses that statistically significant differences would exist in the frequencies of offence actions of Australian and British arsonists, two-way chi square contingency analyses were conducted for each of the corresponding variables. To account for the number of comparisons conducted and to control for Type I error, a Bonferroni adjusted alpha level of $p<.002$ was applied. In addition, a difference was only considered significant if standardised residuals of $\geq 2$ were obtained for the crosstabulation analysis.

\section{Frequencies of Offence Actions}

Several significant differences were found for the frequencies of offence actions of British and Australian arsonists as shown in Table 1. Significantly fewer Australian arsonists set fire to residential property compared to British arsonists, $\chi^{2}(1)=41.19, p=<.0001, d=$ 
CROSS-NATIONAL ANALYSIS OF FIRESETTERS

4.29. The odds ratio was 4.29 indicating that Australian arsonists were four times less likely to set fire to a residential property compared to British arsonists. Australian arsonists were also significantly less likely to have set fire to themself, $\chi^{2}(1)=12.65, p=.001, d=0.54$, to their own home, $\chi^{2}(1)=7.15, p=.008, d=1.93$, to have known their victim prior to setting the fire, $\chi^{2}(1)=10.39, p=.001, d=1.92$, to have been under the influence of a substance, $\chi^{2}$ (1) $=13.99, p<.0001, d=2.815$ or to have planned their offences by bringing with them materials for the purpose of setting fire, $\chi^{2}(1)=26.20, p<.0001, d=2.81$. Compared to British arsonists, significantly fewer fires were started by Australian arsonists in response to a trigger, $\chi^{2}(1)=43.42, p<.0001, d=3.97$, travelled short distances to the scene of their fire, $\chi^{2}(1)=16.15, p<.0001, d=2.26$ or endangered lives, $\chi^{2}(1)=54.92, p<.0001, d=4.47$.

In contrast, Australian arsonists were more likely to have set fire to vehicles, $\chi^{2}(1)=$ 29.12, $p<.0001, d=3.42$ compared to British arsonists. The odds ratio was 3.42 , indicating that Australian arsonists were over three times more likely to have targeted a car compared to British arsonists. Australian arsonists were also more likely to have used accelerants, $\chi^{2}(1)=$ $33.48, p<.0001, d=3.24$; had multiple seats of fire, $\chi^{2}(1)=34.62, p<.0001, d=3.54$, had an accomplice, $\chi^{2}(1)=7.73, p=.005, d=1.78$ and to have not alerted the relevant authorities, $\chi^{2}(1)=21.70, p<.0001, d=4.37$.

\section{Discussion}

Previous researchers have noted differences in the offence actions and background characteristics of arsonists after comparing the findings of their study to the results of other arson research (Hakkanen et al., 2004; Wachi et al., 2007). However, thus far, no other study has attempted to explore whether these observed differences are statistically significant and whether they warrant further investigation. The current study attempted to address this limitation by statistically evaluating whether differences existed in arson variables between two national samples. It was hypothesised that significant differences in arson variables 
CROSS-NATIONAL ANALYSIS OF FIRESETTERS

would exist and further, that they would reflect the environmental or place-based factors of the nation from which each sample was drawn.

Firstly, the study successfully replicated the faceted action systems model that was originally identified by Canter \& Fritzon (1998) and Fritzon, Canter and Wilton (2001). While some specific configural variations were identified, these were by no means incompatible with basic action systems theory, and were consistent with the overall interpretation of actions within each of the four themes. The differences primarily related to variations in the targets and locations of actions, e.g. the targeting of schools in Australia is associated with an individual having committed prior arson, whereas in the UK, schools are more likely to form part of a spree.

Several significant cross-national differences were found when the offence action variables for the Australian sample were compared with the offence action variables for the British sample. As expected, differences found in the offence actions of arsonists appeared to reflect the environmental characteristics of the Australian landscape (Cozens \& Christensen, 2011). For example, the variables Accelerant and Multiple Seats were found in significantly higher frequencies in the Australian sample. Australian arsonists were also more likely to have travelled greater distances and to have set fire to vehicles. In contrast, fires in the Australian sample were less likely to have posed a direct threat to human life or to have included residential property. Australian arsonists were also less likely than British arsonists to have planned for their fire or to have responded to a trigger.

These findings appear to support the environmental perspective, that the actualisation of crime is a reflection of the person-situation interaction (Brantingham \& Brantingham, 1981; Cozens \& Christensen, 2011). It could be argued that the combination of the aforementioned variables supports the possession of skills (or actions) required for the manipulation of the Australian landscape. Multiple seats of ignition and the use of fire 
CROSS-NATIONAL ANALYSIS OF FIRESETTERS

accelerants such as petrol would be more likely to aid in the destruction of large scale bushland. Likewise, the reduced threat to human life in the Australian sample may also reflect the deliberate setting of bushfires or grassfires.

Another possible explanation for the reduced threat to human life in the Australian sample may be that because Australia is far less densely populated than Britain, the targeting of bushland as opposed to residential property is less likely to pose a direct threat to human life. These results also appear to reflect the trend in Australia, for fires to occur at the urbanrural fringes of cities as reported by Cozens and Christensen (2011) and are consistent with Rational Choice Theory, in that the decision to target bushland may be associated with reduced risk of detection for the arsonist.

Also consistent with the work of Cozens and Christensen (2011) were the high frequencies of fires that targeted vehicles also found in the Australian sample of this study. As with the reduced threat to human life, these differences may be attributable to differences in the distribution of the population across Australia and Britain. It is possible that Australia's low density population in rural areas offers to offenders more secluded locations to act out their crimes of arson, where the likelihood of receiving unwanted attention is diminished and the likelihood of an undetected escape is heightened (Cozens \& Christensen, 2011).

It is also possible that this difference may reflect differences in the policing or recording of offences, such as an individual who steals a car and sets fire to it, may then be charged with the theft of a motor vehicle and criminal damage rather than arson per se. Due to difficulties in establishing whether the vehicle offender or another individual was directly responsible for the fire, the second charge may then be dropped. However, where there are higher rates of co-offending as in the Australian sample, it is possible that the addition of the co-offender's account of events may result in a higher likelihood that the arson charge is 
CROSS-NATIONAL ANALYSIS OF FIRESETTERS

upheld. Last, based on the geographical mass of the Australian continent in comparison to Britain, it would be expected that Australian offenders would have to travel greater distances between locations.

The current study's findings provide useful information about the potential for differences to exist in the way that crimes of arson are expressed across different countries. These results also emphasise the potential contribution that environmental criminology theories such as Routine Activities Theory and Rational Choice Theory could make to understanding variations in arson profiles. In a policing context, our findings have important implications for law enforcement agencies that have relied upon profiling models first established in countries like the United Kingdom to explain crimes of arson and apprehend arsonists in their own countries.

The results of the current study are likely to have clinical implications too. If crimes of arson differ in their expression and basic underlying theme, then it is likely that tools for assessing risk and strategies for treating arson behaviours should also differ. Treatment providers and risk assessors will need to look beyond mere motive to truly understand this complex behaviour. For instance, in the current study higher frequencies of individuals who had a significant history of problems with alcohol were found in the Australian sample. This may indicate a need for measures of risk used with arsonists in Australia to account for alcohol abuse as a potential risk factor.

Knowledge about how Australian practitioners conduct investigations into individuals who present with fire-setting behaviours is practically non-existent since there is no published research on investigative or clinical aspects of working with such individuals in Australia. It is assumed (perhaps wrongly) that in the absence of such published research, practitioners may look to international literature for guidance. For example, police investigators as part of the National bushfire emergency planning strategy, are now being trained in a national 
CROSS-NATIONAL ANALYSIS OF FIRESETTERS

bushfire investigation course which is based on a US fire marshall training program. Similarly, clinicians performing risk assessments on individuals with fire-setting histories may use existing structured risk assessment protocols such as the HCR-20 (Webster, Douglas, Eaves, \& Hart; 1997). The results of the current study may therefore be helpful to practitioners in relation both to investigative and clinical practices in terms of highlighting behaviours and characteristics that are more characteristic of Australian fire-setters.

Considering the significance of these implications for clinical and law enforcement professionals it would appear that cross-national differences in arson variables warrant further investigation. Future research could identify whether differences in the geographical distancing of arson crimes vary not only as a function of the environment, but as a result of the mode of functioning that the individual's behaviours are associated with. Further, it is important that future research begin to explore alternate sources of change, including how aspects of personality and motivations may differ cross-nationally. Continued research in the area is required in order to assess the overall utility of the '4D' model as an investigatory tool for arson, internationally. The ability to integrate environmental theories into the offenderbased research for explaining differences in crimes of arson shows promising signs for the establishment of a model that is comprehensive enough to account for arson at various levels of analysis and across national samples. 
CROSS-NATIONAL ANALYSIS OF FIRESETTERS

\section{References}

Australian Institute of Criminology. (2011), Crime types: Arson. Retrieved from http://www.aic.gov.au/en/crime_types/property\%20crime/arson.aspx

Bourget, D., \& Bradford, J. M. W. (1989). Female arsonists: A clinical study. Bulletin of the American Academy of Psychiatry and the Law, 17, 293-300. Retrieved from http://www.ncbi.nlm.nih.gov/pubmed/2790226

Brantingham, P. L., \& Brantingham, P. J. (1981). Environmental criminology. Beverly Hills, LA: Sage Publications.

Brantingham, P. L., \& Brantingham, P. J. (2004). Environment, routine, and situation: Toward a pattern theory of crime. In R. V. Clarke \& M. Felson (Eds.), Routine Activity and Rational Choice (pp 259-95). New Brunswick: Transaction Publishers

Canter, D. (2004). Offender profiling and investigative psychology. Journal of Investigative Psychology and Offender Profiling, 1(1), 1-15. doi: 10.1002/jip.7

Canter, D., Bennell, C., Alison, L., \& Reddy, S. (2003). Differentiating sex offences: A behaviourally based thematic classification of stranger rapes. Behavioral Sciences and the Law, 21, 157-174. doi: 10.1002/bs1.526

Canter, D., \& Fritzon, K. (1998). Differentiating arsonists: A model of firesetting actions and characteristics. Legal and Criminological Psychology, 3, 73-96. Retrieved from http://psycnet.apa.org/psycinfo/1998-02978-005

Cohen, L., \& Felson, M. (1979). Social change and crime rate: A routine activities approach. American Sociological Review, 44, 588-608. Retrieved from http://www.cjresources.com/CJ_Crim_Theory_pdfs/

Cornish, D. B., \& Clarke, R. V. G. (1986). The reasoning criminal: Rational choice perspectives of offending. New York, NY: Springer-Verlag 
CROSS-NATIONAL ANALYSIS OF FIRESETTERS

Cozens, P., \& Christensen, W. (2011). Environmental criminology and the potential for reducing opportunities for bushfire arson. Crime Prevention and Community Safety, 13, 119-133. doi: 10.1057/cpcs.2010.24

Doley, R. (2003). Making sense of arson through classification. Psychiatry, Psychology and Law, 10, 346-352. doi: 10.1375/132187103322742176

Doley, R. (2009). A snapshot of serial arson in Australia. Saarbrücken: Lambert Academic Publishing. Pp. 165.

Fritzon, K., Canter, D., \& Wilton, Z. (2001). The application of an action system model to destructive behaviour: The examples of arson and terrorism. Behavioral Sciences and the Law, 19, 657-690. doi: 10.1002/bsl.464

Gannon, T. A. (2010). Female arsonists: Key feature, psychopathologies, and treatment needs, Psychiatry, 73, 173-189. doi:10.1521/psyc.2010.73.2.173

Hakkanen, H., Puolakka, P., \& Santtila, P. (2004). Crime scene actions and offender characteristics in arsons. Legal and Criminology Psychology, 9, 197-214. doi: $10.1348 / 1355325041719392$

Harmon, R. B., Rosner, R., \& Wiederlight, M. (1985). Women and arson: A demographic study. Journal of Forensic Science, 30, 467-476. Retrieved from http://www.ncbi.nlm.nih.gov/pubmed/3998696

Hickle, K. E., \& Roe-Sepowitz, D. E. (2010). Female juvenile arsonists: An exploratory look at characteristics and solo and group arson offences. Legal and Criminological Psychology, 15, 385-399. doi: 10.1348/135532509X473913

Horley, J. \& Bowlby, D. (2011). Theory, research, and intervention with arsonists. Aggression and Violent Behavior, 16, 241-249. doi: 10.1016/j.avb.2011.03.006

Liem, M., Barber, C., Markwalder, N., Killias, M., \& Nieuwbeerta, P. (2011). Homocidesuicide and other violent deaths: An international comparison. Forensic Science International, 207, 70-76. doi: 10.1016/j.forsciint.2010.09.003 
CROSS-NATIONAL ANALYSIS OF FIRESETTERS

Kocsis, R. N., \& Cooksey, R. W. (2002). Criminal Psychological Profiling of Serial Arson Crimes. International Journal of Offender Therapy and Comparative Criminology, 46, 631-.656. doi: 10.1177/0306624X02238159

Ministry of Internal Affairs and Communications Statistics Bureau of Japan. (2011). Monthly Statistics:Culture. Retrieved from http://www.stat.go.jp/english/data/index.htm

Santilla, P., Hakkanen, H., Alison, L., \& Whyte, C. (2003). Juvenile firesetters: Crime scene actions and offender characteristics. Legal and Criminological Psychology, 8, 1-20. doi: $10.1348 / 13553203762871200$

Shye, S. (1985). Nonmetric multivariate models for behavioural action systems. In D. Canter's (Ed.) Facet theory approaches to social research. New York, NY: Springer Verlag

Tonkin, M., Santilla, P., \& Bull, R. (2011) The linking of burglary crimes using offending behaviour: Testing research cross-nationally and exploring methodology. Legal and Criminological Psychology. Advance online publication. doi: 10.1111/j.20448333.2010.02007.x

Trojan, C., \& Salfati, C. G. (2011). Linking criminal history to crime scene behaviour in single-victim and serial homicide: Implications for offender profiling research. Homicide Studies, 15, 3-31. doi: 10.1177/108767910397281

United Kingdom's Home Office of Crime Statistics. (2011). Science, research and statistics: Crime. Retrieved from http://homeoffice.gov.uk/science-research/researchstatistics/crime/

Wachi, T., Watanabe, K., Yokota, K., Suzki., M., Hoshino, M., Sato., A., \& Fujita, G. (2007). Offender and crime characteristics of female arsonists in Japan. Journal of Investigative Psychology and Offender Profiling, 4, 29-52. doi: 10.1002/jip.57 
CROSS-NATIONAL ANALYSIS OF FIRESETTERS

Webster, C. D., Douglas, K. S., Eaves, D., \& Hart, S. (1997). HCR-20: Assessing risk for violence. Burnaby, BC: Mental Health, Law and Policy Institute, Simon Fraser University.

Wortley, R., \& Mazerolle, L. (2008). Environmental criminology and crime analysis. Devon, UK: Willan Publishing. 
CROSS-NATIONAL ANALYSIS OF FIRESETTERS

Author's Notes

Author One:

Dr Katarina Fritzon

MSc (Surrey), PhD (Liverpool), MA Hons (Aberdeen)

Associate Professor/ Co-Director - Australian Centre for Arson Research and Treatment

Faculty of Humanities and Social Sciences, Bond University

Varsity Lakes, Queensland 4229, Australia

Phone +61755952681

kfritzon@bond.edu.au

Author Two:

Dr Rebekah Doley

BA (Hons), Grad Dip Psych Prac, MSc (Inv Psy), MPsych (Clin), PhD

Assistant Professor/Director-Clinical and Forensic Psychology Programs,

Co-Director - Australian Centre for Arson Research and Treatment

Faculty of Humanities and Social Sciences, Bond University

Varsity Lakes, Queensland 4229, Australia

Phone +61755951344

rdoley@bond.edu.au

Author Three:

Kerrilee Hollows

BPsych, Grad Dip Psych, MPsych (Forensic)

Assistant Clinic Director, Bond University Psychology Clinic

Faculty of Humanities and Social Sciences, Bond University 
CROSS-NATIONAL ANALYSIS OF FIRESETTERS

Varsity Lakes, Queensland 4229, Australia

Phone +61755952632

khollows@bond.edu.au 
CROSS-NATIONAL ANALYSIS OF FIRESETTERS

Table 1

Differences in Frequencies of Offence Actions for Australian and British Arsonists

\begin{tabular}{|c|c|c|c|}
\hline Offence Variables & $p$ & $\operatorname{Phi}(\varphi)$ & Odds Ratio \\
\hline Endanger & $<.0001 * * *$ & -.36 & 4.77 \\
\hline Trigger & $<.0001 * * *$ & -.32 & 3.97 \\
\hline Residential & $<.0001 * * *$ & -.31 & 4.29 \\
\hline Multiple Seats & $<.0001 * * *$ & .29 & 3.54 \\
\hline Accelerant & $<.0001 * * *$ & .28 & 3.24 \\
\hline Vehicle & $<.0001 * * *$ & .27 & 3.42 \\
\hline Planned & $<.0001 * * *$ & -.25 & 2.81 \\
\hline No Alert & $<.0001 * * *$ & .23 & 4.37 \\
\hline Distance & $<.0001 * * *$ & -.20 & 2.26 \\
\hline Substance & $<.0001 * * *$ & -.18 & 2.15 \\
\hline Self & $<.0001 * * *$ & -.17 & .54 \\
\hline Victim Known & $.001 * *$ & -.16 & 1.92 \\
\hline Multiple Offenders & $.005 * *$ & .14 & 1.78 \\
\hline Home & $.008 * *$ & -.13 & 1.93 \\
\hline School & .124 & -.08 & \\
\hline Finance & .235 & .06 & \\
\hline Business & .207 & .06 & \\
\hline Institution & .341 & .05 & \\
\hline Outburst & .414 & -.04 & \\
\hline Witness & .403 & .04 & \\
\hline Remain/Return & .738 & .02 & \\
\hline Multiple Item & .946 & .02 & \\
\hline
\end{tabular}

${ }^{*} p<.05 .{ }^{* *} p<.01 .{ }^{* * *} p<.001$ 


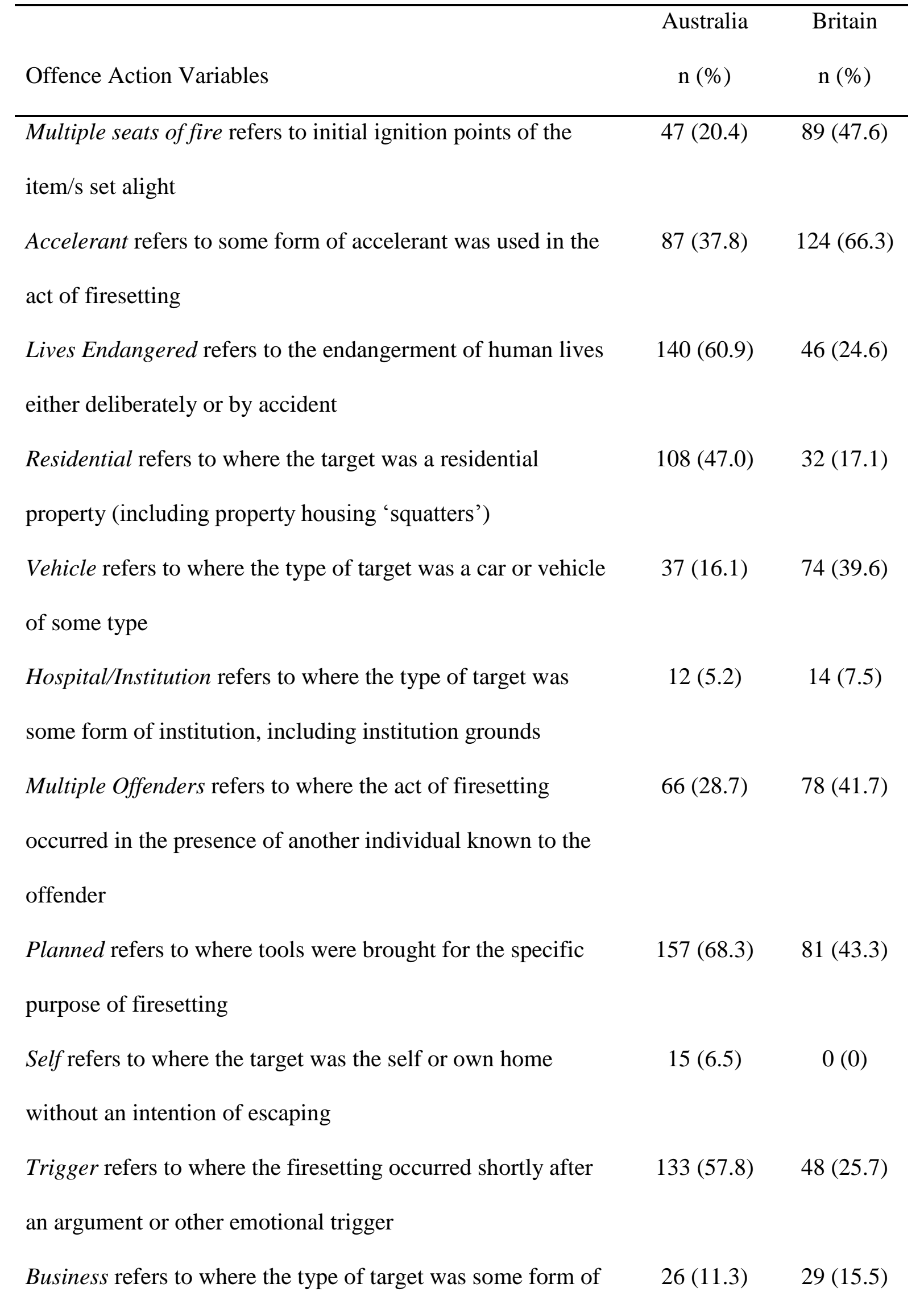


CROSS-NATIONAL ANALYSIS OF FIRESETTERS

commercial property

Victim Known refers to where the victim of firesetting was

$155(67.4) \quad 97(51.9)$

known to the offender including a (ex) partner

Own Home refers to where the type of target was an own

$62(27.0) \quad 30(16.0)$

home (coded in addition to residential and/or self)

Prior Arson refers to where an offender has set fires prior to

$58(25.5) \quad 39(20.9)$

the current offence, including self-reported prior fires

School refers to where the type of target was some area of

$15(6.5)$

$6(3.2)$

school grounds

No Alert refers to where the offender left the scene of fire and

$177(77.0)$

$175(93.6)$

did not alert the relevant authorities e.g., fire brigade

Witness refers to where firesetting took place in front of

$44(19.1) \quad 42(22.5)$

person/s who were not willing participants

Remain/Return refers to where an offender remained at the

$102(44.3) \quad 86(46.0)$

scene or returned to the scene while the fire was still burning

Outburst refers where the fire appeared to be a 'frenzied

$40(17.4) \quad 27(14.4)$

attack' containing multiple seats \& items of fire

Substance Use refers to where the offender consumed some

$13(49.1) \quad 58(31)$

form of mind or mood altering substance prior to lighting fire

Distance refers to where the distance travelled to the offence

$159(169.1) \quad 92(49.2)$

scene was $<5$ kilometres

Finance refers where the offender believed he/she was to

$18(7.8) \quad 21(11.2)$

benefit directly from fire, financially or otherwise

Multiple items refers to the number of objects that landed up $93(40.4)$ on fire excluding secondary objects used to light fire 


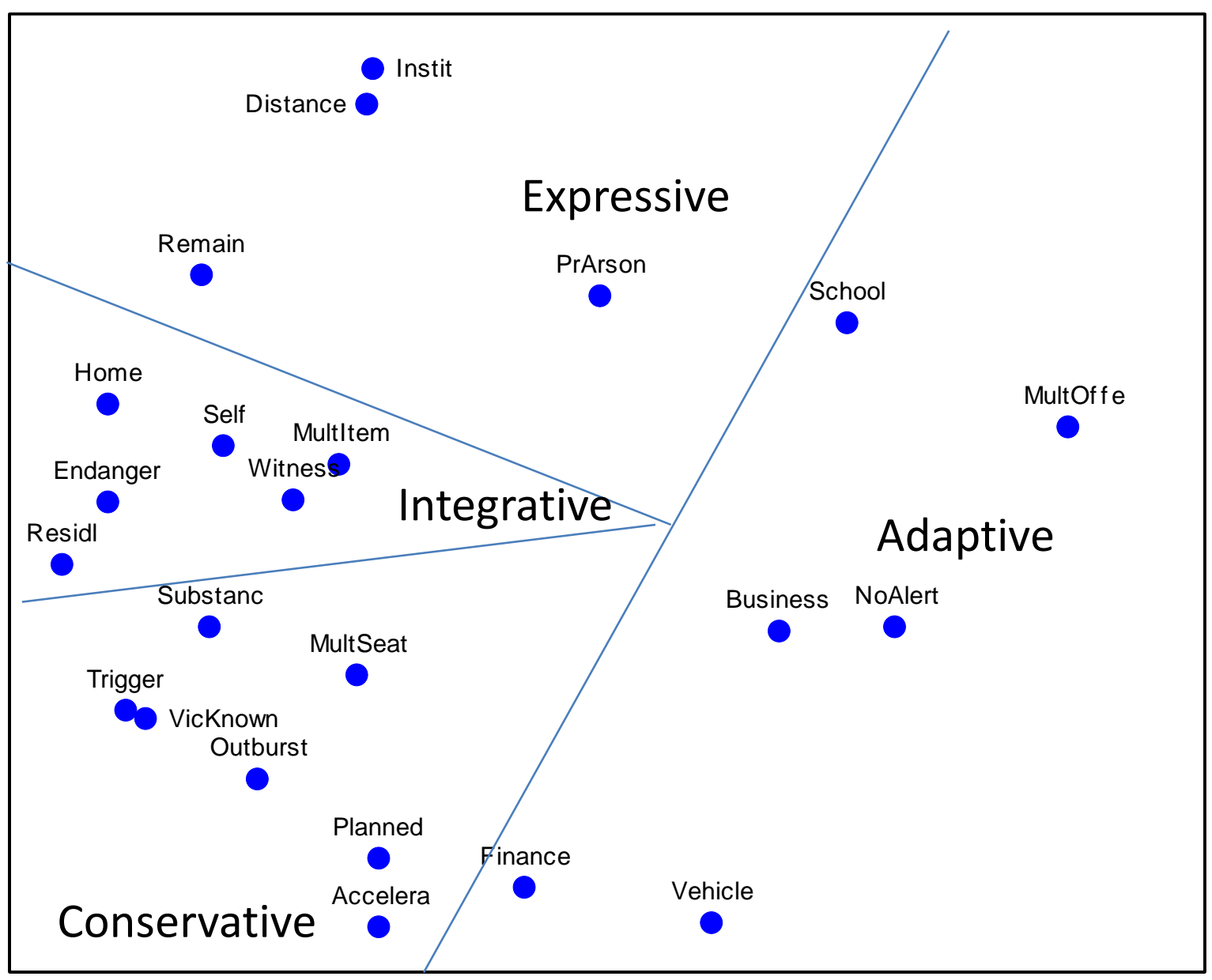

Figure 1: SSA of UK police cases $(n=238)$ 


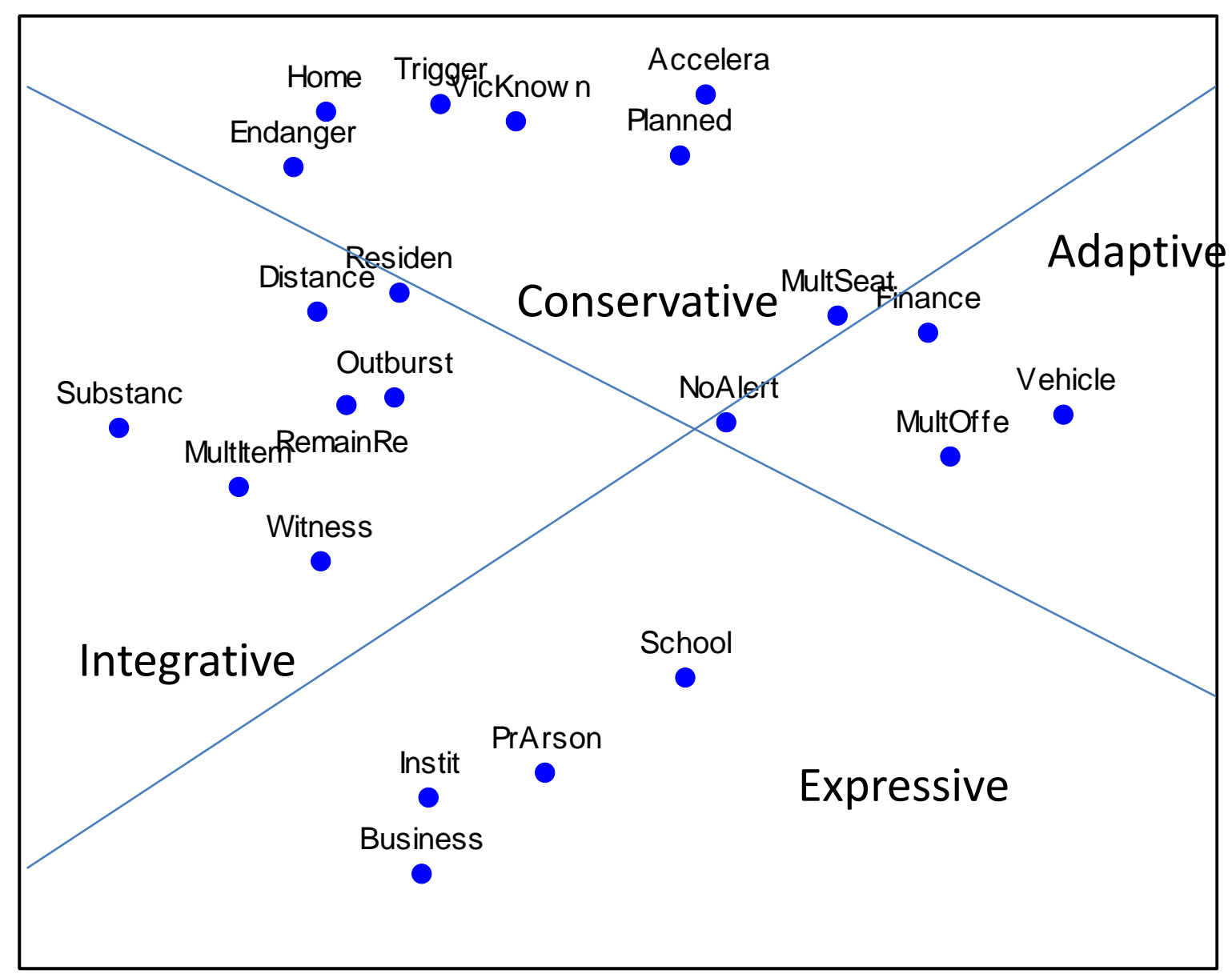

Figure 2: SSA of Australian police cases $(n=187)$

\section{End Notes}


CROSS-NATIONAL ANALYSIS OF FIRESETTERS i Within this paper, the terms 'arson' and firesetting' are used interchangeably. Arson is the legal definition
while, firesetting describes the behaviour itself.
ii Police data used in the Wachi et al. (2007) study was processed in such a way that, information about multiple
arson offences, committed by the same individual were summarised within one police file. 